\title{
Datafication of Knowledge Work: A Framework and Research Agenda
}

\author{
Louise Harder Fischer \\ IT University of Copenhagen, Denmark \\ louf@itu.dk
}

\author{
Nico Wunderlich \\ IT University of Copenhagen, Denmark \\ nicw@itu.dk
}

\begin{abstract}
Datafication is moving into the center of value creation in the knowledge intensive organization. Datafication describes the transformation of qualitative behavior and tacit knowledge into quantified actions and codified data. While traditional assumptions on knowledge work highlights individual autonomy in shaping job tasks and fitting abilities for productive work, the consequences of datafication for knowledge work are not yet well understood. We build on the contingency theory of performance as theoretical lens to derive a framework that addresses relevant future research questions in the evolving field of datafication in knowledge work. The proposed multi-level framework considers assumptions and elements from traditional productive knowledge work in combination with determinants of digital workplaces and organizational factors along the lines of data-based value creation and (semi-)automated decision making. For the future, we suggest viewing datafied knowledge work as a socio-technical phenomenon, thereby constituted of human-dominated knowledge work in convergence with technological-dominated algorithmic thinking.
\end{abstract}

\section{Introduction}

Digital technologies play an increasingly important role in the quest for organizing the most feasible digital enablement of tasks in knowledge intensive corporations, and as an integral part for relevant aspects of operating, controlling, and coordinating activities [42]. More generally, digital technologies are used for automating and augmenting tasks, in collaborative decision making among digital and human agents, and for communicating internally among organization members and externally with customers and partners [12]. Progressively, digital technologies are adopted in knowledgeintensive organizations to provide data to inform decision-making and pursue strategic objectives by extracted information and knowledge.
A basic assumption around knowledge work (KW) is that it is non-routine, ever changing, and dynamic, and therefore requires innovative and autonomous methods [14]. Knowledge professionals are the locus of value creation in these settings, since the term $\mathrm{KW}$ refers to individuals contextualizing data into actionable information, that becomes valuable knowledge in the minds of those knowledge workers [2, 12, 33]. For decades, the dominant mantra of how to improve the outcome of KW has centered around how human individuals turn information into knowledge to make good decisions [30, 33]. While technological development in the knowledge intensive workplace has a long history $[2,11,19]$, the recent onus on the generation of data as a central part of the digital economy brings about particular transformational tensions that deserve further attention [38].

In the pursuit of productivity and improved competitiveness, the use and need for critical business data in combination with the deployment of emergent technologies such as robots, automation, business- and artificial intelligence as well as machine learning algorithms has brought about a phenomenon labeled organizational datafication. Organizational datafication refers to the move of turning tacit knowledge and social action into data [40]. Organizations thus become data-driven when data is acted upon by human and digital actors [12] and when the strategic framing reflects, favors, and guides the relevance of data for the entire organization [5]. In this paper we inquire into determinants of datafied knowledge-work systems and ask the overall research question, how datafication impacts knowledge work.

While research on the development, use, and consequences of organizational datafication has increased in recent years $[6,38,40]$, an under-researched phenomenon is how datafication affects and changes the nature of KW. This paper establishes an agenda and a research framework to initiate research in datafication of $\mathrm{KW}$. We propose novel research questions that shall lead to promising future studies and theory building. We explore this growing workplace phenomenon from a socio-technical perspective [34], as it builds on human- 
dominated $\mathrm{KW}$ and technological developments resulting in datafication. This reflects the increasing interlocking of social artefacts with technical artefacts into one system of today's work environments. The corresponding digital convergence of digital infrastructure with organizational structure has brought forth organizational concepts such as digital business strategies [5, $21]$ that describe strategic consequences of this congruence of business and IT. In this context, multi-sided business models demand exploiting the massive amounts of data resources in digital ecosystems to understand and adapt to this highly interconnected and ever-changing business environment. With this prominent status of data for organizational value-creation, automated decision making and machine learning analytics increasingly assist humans in coping with those growing options of gaining information - while this computed knowledge shows potential to substitute its human creation in parts. As this digital transformation in knowledge-intensive enterprises implies an adaption of KW settings, we develop a multi-level understanding of the elements of what we label datafication of KW. The results provide researchers and managers insights into determinants for future work-system design.

As underlying theoretical framing, we refer to the contingency theory of action and job performance, that we transfer from leadership research to the field of $\mathrm{KW}$ and its advanced professionals in line with suggestions from the original publications $[7,8]$. This theory leads our operationalization of the social dimension of $\mathrm{KW}$ in a process model of job tasks, individual abilities, and individual performance; and the technological dimension of datafication into individual (e.g. IT competencies) and organizational factors (e.g. digital business strategy, knowledge management systems and data-driven decision support). Further attention is given to job autonomy as an integral element in $\mathrm{KW}$, and how it might be positively and/or negatively influenced by datafication.

We have structured the paper as follows. In section 2 , we provide a critical analysis of central in-house assumptions around how to organize and enable productive $\mathrm{KW}$ in the knowledge intensive corporation. In section 3 , we develop a framework that contributes to a deeper understanding of the emergent field of datafied $\mathrm{KW}$ through combining elements of traditional $\mathrm{KW}$ with factors of datafication. In section 4 we summarize and synthesize our propositions, especially in the direction for future research.

\section{Assumptions on associating traditional knowledge work with datafication}

The nature of digital and emergent technology underlying datafication, represents a simplistic view of the tasks it supports and the structures it represents. Datafication is associated with algorithmic thinking [36]. Algorithmic thinking opens a path to task solutions through the clear definition of automated steps and approaches in a routinely repetitive manner and with predictive outcomes [36]. In comparison, the view on traditional KW represents a more holistic perspective on tasks: Each task is individually and contextually defined and carried out in socio-technical arrangements that are continuously fitted to the situation, as are the abilities of the job [34]. As a consequence, to create value, knowledge workers are used to incessantly innovate, learn, and improve practices and knowledge with unpredictive outcomes [14]. Thus, Drucker defines autonomy as a central determinant to productivity and valuecreation in KW [14]. Consequently, the nature of $\mathrm{KW}$ and of datafication are very different.

Inspired by Alvesson and Sandberg's problematization methodology for generating novel research questions [3], we identify and problematize in-house assumptions from influential research on the subject. Through dialectical interrogation we arrive at five central problematizations around classic $\mathrm{KW}$ that arise when linked to datafication.

\subsection{Personal judgement and intuitive decision- making}

A common assumption around $\mathrm{KW}$ is that it mainly centers around taking good decisions and solving problems, and that the abilities to do so derive from knowledge professional's individual creativity and deep experience [33]. Datafication, with an inherent underlying algorithmic thinking, has a huge impact in the digital workplace [38] as it builds on codification and fragmentated tasks; and that everything that can be codified, will be codified [12]. The usage of big data, robots, automation and machine learning deliver benefits for management [48]. With data, managers can measure, and hence know, radically more about their businesses, and directly translate that knowledge into improved decisionmaking and performance [29]. According to Brynjolfson and McElheran [9], data-driven decision making has tripled between 2005 and 2010, and seems to have increased productivity. However, the ongoing push for big data/data science presupposes the quantification of qualitative phenomena. The core of $\mathrm{KW}$, the qualitative - judgements, assessments, sense-making is being challenged by quantification through Big Data/datafication inspired by new digital tools such as sensors and BI-platforms [31]. While learning can happen from facts by combing through databases, and some true correlations are observed by running sophisticated algorithms over massive amounts of information, 'knowledge' is not the result. It results from a far more 
complex individual process that is personal, goaldriven, contextual, and culturally-bound [48]. The closer ones look at data-driven decision making one observes a rejection of gut feeling, intuition and experience [36]. When we link these two in nature different phenomena we problematize as follows: When data-driven decision making and -support is at the core of datafication, the qualitative nature of knowledge work such as intuition, personal judgement and experience, will assume a different role in value-creation.

\subsection{Individual autonomy}

For KW to deliver real value and competitive advantage to the organization, knowledge professionals must have full autonomy to define what is the task and what methods and steps are necessary to take to fulfill that task. Autonomy is the single most important determinant to performance [14]. In turn, on-going value-creation and productivity involve the ability to continuous innovate, learn and bring about best practices [14]. Complex and non-routine $\mathrm{KW}$ seldom has one single correct or standard output, nor are those outputs usually quantifiable or comparable [32]. Drucker [14] defines six factors to improve outcomes from KW. The six factors are: Knowledge profesionals must identify the tasks themselves; they need autonomy; Innovation has to be a part of $\mathrm{KW}$; knowledge requires continuous learning and teaching; $\mathrm{KW}$ is primarily a matter of quality and not just quantity; And KW should be seen as an asset instead of a cost [14]. According to Drucker, this sparks productivity in terms of creative outcomes and competitive advantage, that can be evaluated. When we link these assumptions around $\mathrm{KW}$ to datafication we problematize it as follows: When data is codified, and practices and processes are turned into steps and algorithmic rules, individual autonomy in knowledge work over task-definition, techniques and approaches to carry out work; and to innovate, learn and improve abilities, will assume a different importance in value-creation and outcomes.

\subsection{Knowledge as competitive advantage}

'Knowledge' per se, delivers competitive advantage to companies. Managing and cultivating the intangible and non-routine process of knowledge creation is central to the knowledge creating company. Nonaka's [33] approach to managing knowledge, recognizes that valuable KW depends on tapping the tacit and often highly subjective insights, intuition, and hunches of individual employees; and making those insights available for testing and usage for the company as a whole. This management paradigm assumes that individuals create knowledge, yet if properly organized, the organization can reinforce a spiral of knowledge creation, involving four generic stages: Socialization among members to share tacit knowledge; Externalization of tacit knowledge in groups as new concepts and models; Combining this new knowledge with existent organizational knowledge; and then transferred back to members as internalized new knowledge. Consequently, a basic assumption defining knowledge is that it is a fluid mix of framed experience, values, contextual information, expert insight and grounded intuition that provides an environment and framework for evaluating and incorporating new experiences and information [13]. Knowledge originates and is re-applied in the minds of knowers, and as a consequence of this process, knowledge is embedded not only in documents and repositories but also in organizational routines, processes, practices and norms [13]. Knowledge is personalized information (which may or may not be new, unique, useful, or accurate) and it is related to facts, procedures, concepts, interpretations, ideas, observations, and judgments [2]. When we link these assumptions around KW to datafication and the now data-intensive corporation, , we problematize as follows: When data is becoming a new valuable resource, 'knowledge', as the most valuable asset created and possessed by individuals and reinforced by the organization, will assume a different status.

\subsection{Knowledge Management Systems}

Supporting KW with the right technology is a widely accepted approach to spark productivity and performance. As such information technology plays an important role in capturing, storing and disseminating knowledge between individuals, groups, and the organization. The focus lies on the Knowledge Management Systems (KMS) [2]. The difference in support from KMS relies on the organization's need of sharing either tacit or explicit knowledge [19]. Tacit knowledge is shared through a people-to-people approach, while explicit knowledge is codified and shared through a people-to-document approach [19]. To improve performance Davenport [11] explains, that some tasks and some knowledge workers need a free access approach, while other tasks and knowledge workers rely on a provisional-structure approach. The free-access approach gives knowledge workers free access to a wide variety of tools and information resources. It assumes that these employees determine their own work processes and needs. The structured provision of information and knowledge approach delivers information to employees within a well-defined context of tasks and deliverables. Computers send batches of work to employees and provide the information needed to do it. Free-access and 
structured-provisioning approaches make radically different assumptions about how KW should be performed and how productivity and performance is improved [32]. While the free access approach has a risk of creating too many disruptions, information overload and increasing task complexity, the structured provision approach reduces the knowledge workers' autonomy by introducing routine and repetitiveness into tasks [11]. The structured provision approach resembles algorithmic thinking underlying datafication, thus we problematize this: Datafication predominantly builds on centralization of data and standard approaches to carry out tasks through codification and algorithmic thinking, thus KMS approaches that takes tacit knowledge and autonomy into account seems less valuable in value-creation and performance.

\subsection{Knowledge Management Strategy}

A basic assumption around knowledge management strategy is that it follows the competitive strategy laid out by the business [19]. When a company competes on price, it primarily establishes standard procedures and reuse of information and favors repositories with codified knowledge that support routine work to reduce costs. On the other hand, when a company competes on differentiation it relies on creative problem solving and non-routine approaches, and experts are supported in collaborating and how to create new knowledge [19]. In the datafied workplace, a digital business strategy (DBS) determines as one sole concept how to leverage digital resources to create business value [5]. This fusion manifests the all-embracing role of IT in today's competitive business, particularly the rise from the functional supporting role to the strategic firm level [23]. The concept of the digital business strategy addresses an encompassing catalogue of aspects on how the congruence of the digital with the organizational structure affects a firm: The cross-functional concept encompasses the entire organization and especially describes breaking up functional silos for intra-firm cooperation. Further, the dynamic model pronounces the external relations to the competitive landscape of acting in extended digital ecosystems by multi-sided business models and digital supply chains. This internal and external interplay emphasizes the function of network and platform architectures, that enable the scalable and flexible reconfiguration of resources as well as accelerated cycles of sensing, responding, and innovation. The number and frequency of the required decisions in those dynamic business environments is based on data, the key resource in digital business [4]. Accordingly, a DBS explicitly determines a company's value creation deriving from data and the processed information, when the organiza- tional boundaries for innovation and the continuous dynamic processes of sensing and adapting to the business environment are blurring [51]. While research already investigates the consequences of a DBS for leaders and leadership in the digital age $[4,35]$, we problematize how a digital business strategy affects the job tasks in datafied knowledge work when traditional KM strategies aiming at specific types of knowledge creation (tacit/explicit) and task performance (routine/non-routine), lose importance.

In summation, we identify and problematize several in-house assumptions around the nature of traditional KW and related management approaches for value-creation and performance which are challenged by datafication. The phenomenon of datafication impacts and changes the nature of $\mathrm{KW}$, at the individual level and at the level of the organization. Respectively, the reliance on intuition, experience, personal judgement in decision-making and problem-solving is challenged. Individual autonomy over tasks and techniques therefore becomes questioned, traditionally improving abilities through continuous learning and creation of new knowledge. At the organizational level, we identify challenges for the established human-dominated processes around knowledge as the most important asset, such as the self-reinforcing spiral of moving between tacit to explicit knowledge as well as the support from KMS for knowledge-intensive tasks and competitive strategies. Overall, technological development has brought approaches to improve individual performance and organizational outcomes to support a growing fragmentation of KW into smaller tasks. This tendency fundamentally changes what used to be a whole self-defined task and qualitative in nature, into sets of predefined smaller tasks, that are much more quantitative. An open question remains what the consequences of this move are and how this affects demands for abilities to perform productive $\mathrm{KW}$. While the impact and usage of technical and digital components in work-systems dominates [39], we especially promote and highlight the social component in the next sections by approaching datafication of $\mathrm{KW}$ as a socio-technical phenomenon.

\section{Framework for Exploring the Datafica- tion of Knowledge Work}

In the following section we generate a framework to further understand the evolving phenomenon of datafication of $\mathrm{KW}$, its determinants, and their relations. The overarching socio-technical perspective helps us to fundamentally structure the regarded phenomenon into the dimensions of KW ('socio') and datafication ('technical'). Boyatzis' contingency theory of action and job performance as underlying theoretical framing allows to 
subdivide those dimensions into operationalizable constructs on both organizational and individual levels [7], such as job tasks, job abilities, and job performance for the process chain of $\mathrm{KW}$ as well as data-driven moderators from the organizational and the employee's perspective. As a performance theory, the contingency theory describes how the congruence of the three dimensions (figure 1): 1. a person's abilities with 2. the job demands and 3. the organizational environment, result in increased individual performance $[7,8]$. This theory was developed in the field of research on leadership, and the authors particularly mention the applicability for advanced professionals. Accordingly, we constitute the theory as a valuable blueprint for structuring the context of $\mathrm{KW}$ in reflection of the associated degrees of required job autonomy in both $\mathrm{KW}$ and leadership [11, 14, 33]. The framework serves as a conceptual foundation to model the phenomenon of datafication of $\mathrm{KW}$, to raise its understanding and to develop research questions from. As a result, we draw a fundamental process model of $\mathrm{KW}$ in which we interlace further elements of influential factors and organizational conditions of datafication, see figure 2.

As a first step, we reflect $\mathrm{KW}$ in a general process structure through relying on Boyatzis' framework [8] and converting factors from his theory (figure 1) into a process model of KW (figure 2). From the individual perspective of a $\mathrm{KW}$, we represent the job task and the abilities to fill the respective demands in a consecutive process for achieving individual performance. Since KW does not predominantly consist of standardized tasks, we pay respect to Drucker's findings around autonomy in $\mathrm{KW}$ in perpetuating both task definition as well as selection and development of required abilities by individual knowledge workers [11, 14]. While job tasks are also (to some extent) determined by the business strategy of the organization, we point out potential organizational effects on task definition in datafied $\mathrm{KW}$ to be further discussed in the context of datafication. Traditionally, KMS are seen as valuable organizational support for individual's decision making [2], which is why we implement KMS as an established factor to enhance the impact of knowledge worker's skills on individual performance. Equipped with this basic understanding of KW as a process of autonomous task definition and knowledge-supported abilities in achieving individual performance, we are ready to put it to the test against the evolving challenges arising from datafication.

Approaching the context datafication of $\mathrm{KW}$ in a second step, we single out the attribute of tasks from Boyatzis' first sub-dimension of job demands (see figure 1), since the autonomous definition and selection of tasks in $\mathrm{KW}$ was highlighted as an important determi- nant to performance $[11,14]$. From the individual attributes, we depict job abilities and competencies, as the nature of $\mathrm{KW}$ is changing from being social, intangible, and non-routine, to more technical, tangible, and routine $[31,48]$. Thus, for future analysis, we are interested in if and how datafication impacts task autonomy, especially if it results in increased or decreased autonomy. Potential transformational forces may be directed from algorithmic thinking and the (semi-)automated, while data-based decision making in contrast to the traditional perspective of knowledge being created by humans [33].

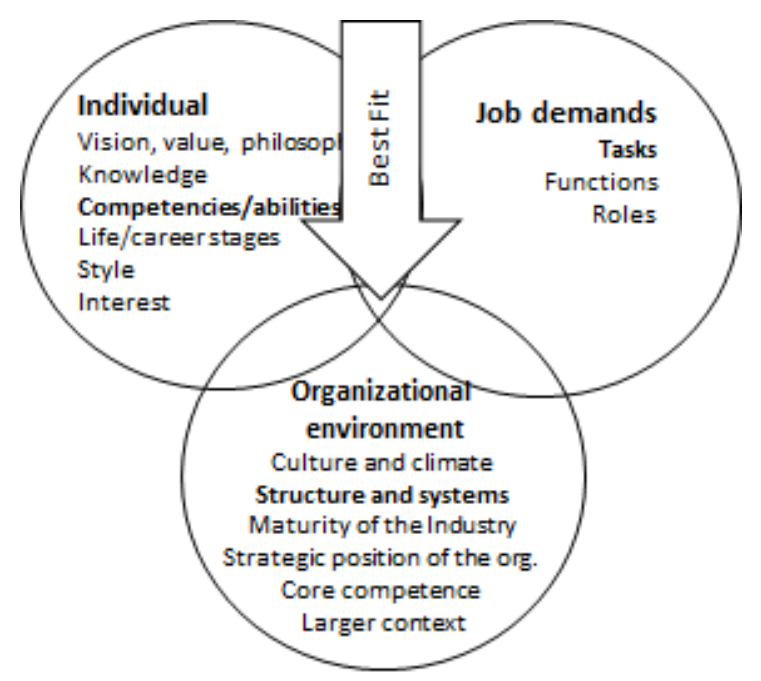

Figure 1. Theory of action and performance [8]

In addition, we are interested in if and how abilities and competences, that particularly comprise IT-skills, impact performance. From the organizational work environment, we address attributes of structure and systems, such as how (datafied) job tasks in KW are shaped by the extent of an enacted DBS, since this strategic concept manifests the organization's commitment to the importance of data for its multi-sided digital business model [5]. In the same line, we discuss the influence of traditional KMS in comparison to the artificial intelligence and learning machines for adopting (semi-)automated decision making through data analytics [27]. Research in datafication of $\mathrm{KW}$ will have to discuss the potential strategic dominance of the value of data and decision automation against the proven advantages of individual autonomy in KW. Finally measuring productivity, we take individual job performance into account as an outcome variable of datafied KW that synthesizes the fit of the triple of job demand, individual ability, and organizational factors, as intended by the contingency theory of action and job performance $[7,8]$. 
To provide a framework for investigating the sociotechnical phenomenon in more detail, we reflect the subdimensions derived from the contingency theory in more interweaved interrelations to explore the context of datafication. We suggest two operational research questions:

RQ1: How does datafication determine the definition of job tasks in knowledge work?

RQ2: How does datafication shape the process of productive knowledge work?

As displayed in figure 2, we reflect the dimensions of the contingency theory of job performance in a concretized framework for studying datafication of $\mathrm{KW}$, that particularly brings the theoretically derived components into more substantial relations. In the following sections, we discuss those theoretically derived interrelations that particularly focus on changes in the digital and datafied workplace, in order to draw from these arguments to future research opportunities.

\subsection{Foundations for RQ1}

Knowledge-intensive organizations are facing substantial changes in digital infrastructure, since computing power, lower cost for data storage, and connectivity based on a faster and wider internet change its business environment [48]. Whereas organizational culture such as mindfulness were verified to improve the assimilation of IT innovations in business processes of incumbent firms [50], the recent developments of digital infrastructure reshape the entire business strategy and business models [45]: Global connectivity creates digital ecosystems of highly intertwined, co-creating customers and suppliers, resulting in platform businesses, where every (trans)action is reflected, tracked, and stored in (big) data [21]. The developments are not limited to creating value for customers by producing more individualized services, automated decision-making or meta-human systems also generate socio-technical developments that shift data at the center of attention [28]. A DBS represents a theoretically developed framing of how to gain business value from the evolving role of data and digital technology in organizations and is derived from a fusion of the formerly separate IT strategy with the overall business strategy into one sole concept [5]. Organizations executing a DBS leverage more value from IT resources and realize IT-enabled innovativeness through increasingly involving their employees [23, 51]. Whereas further reaching consequences for KW are still unknown [32], studying knowledge-intensive organizations pursuing a DBS promise fertile insights into how datafication impacts KW. It is an open question, if digital, data-driven business models impact knowledge workers in the same way that manufacturing workers were affected through automation [27]. Davenport highlights that task complexity is minimized when KW takes a structured provision approach [11], however, this approach also minimizes autonomy. While a decrease in task complexity can have a positive impact on individual performance, a decrease of task-autonomy might have a negative impact.

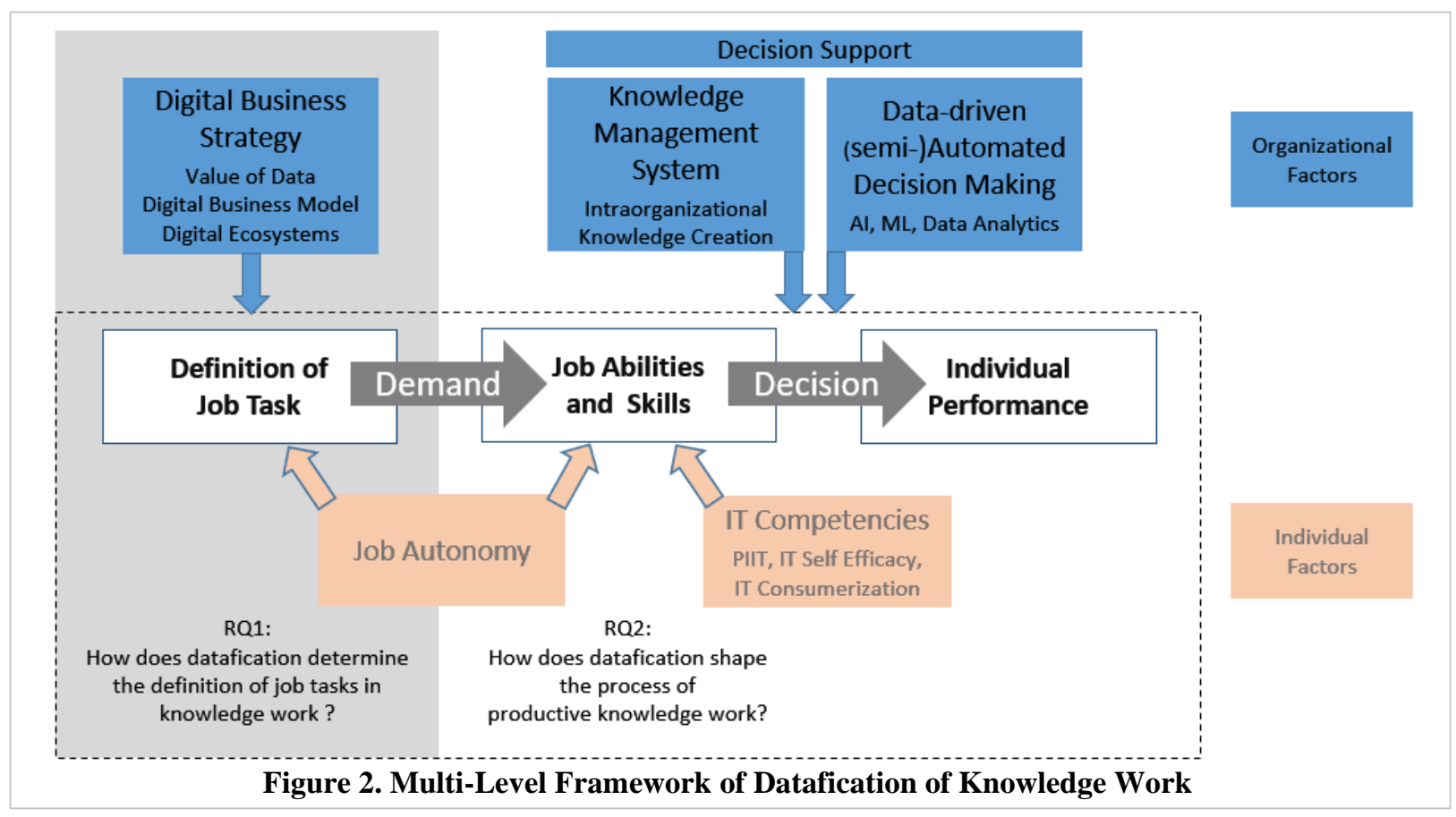


Therefore, it is of paramount importance to see the implications in knowledge work performance, when the job-task definition moves from the level of the individual to the organizational level - put forth by the digital business model. This move changes the autonomous elements of knowledge work substantially, as creative thinking and problem-solving, of how to define the task and approach it, diminishes.

\subsection{Foundations for RQ2}

Addressing RQ2, we consider factors from both the individual and the organizational level which help to provide a first understanding about their interplay in shaping productive $\mathrm{KW}$ in data-intensive organizations. Following the contingency theory displayed in figure 1, we focus with RQ2 on the interrelations around changing job abilities and required skills, thereby continuing exploring the underlying assumption of RQ1 in which decreased work autonomy through datafication is supposed to impact performance. In particular we discuss the developing demands for skills and abilities by drawing on relevant theories of datafication and devote our focus on discussing job autonomy against IT-competencies at the individual level in this step. For the organizational factors, we consult the established decision support through KMS in comparison with the emerging and data-driven perspectives of decision-making. Since information and knowledge-based decision making is inherent to $\mathrm{KW}$, we assume impacts of these consequences of datafication on the knowledge worker's productivity in the shape of individual job performance.

3.2.1 Individual IT competencies complementing knowledge worker's job abilities. While work environments convert to dynamic and decentralized configurations composed of global connectivity, technological improvements, digital competition, and short frequencies of innovation, organizations grow dependent on employees who easily adapt to those changing conditions rather than relying on executing defined tasks [16]. Particularly knowledge workers with high-level and non-routine tasks comply with these conditions and are challenged to improve knowledge, skills, and abilities in respect to fluid demands [43]. To cope with the emerging phenomenon of datafication, we suggest IT-related individual competencies as positively influential on job performance that are proven to enhance the engagement with new features or applications of IT in work environments. IT self-efficacy expresses an individual's belief in the competence to use IT in successfully supporting their work [22]. Recent research demonstrates how IT self-efficacy strengthens proactive work behavior, that in turn incorporates aspects of $\mathrm{KW}$ such as problemsolving and individual innovativeness [44]. To further draw on innovativeness, personal innovativeness especially in information technology (PIIT) is subsumed as "the willingness of an individual to try out any new information technology" (1, p. 20) and sequences an individual's perceptions about innovative IT. PIIT correlates positively with IT self-efficacy and lowers computer anxiety at work [46]. We ask how PIIT and IT selfefficacy might stimulate a proactive individual motivation to successfully cope with the innovative challenges of datafication in KW environments. Likewise in their everyday life, the increased usage of digital technologies such as smartphones, social media, or online shopping and banking recently originated the phenomenon of consumerization of IT $[18,51]$. This phenomenon, sometimes similarly proclaiming 'pro-workers', may be compared to the emergence of 'pro-sumers', (co)producing customers in co-creating digital services [24, 41]. Knowledge workers also demonstrate both enhanced IT competencies to (partially) cope with the changing nature of datafied KW as well as expectations against how to interact with IT at work. In general, person-job fits express inter alia the congruence of individual skills of employees with the respective demands of the job and describe how employees close the gap between demands of the work environment and individual abilities. This complementary coherence is referred to as demands-ability fit $[10,26]$. As a phenomenon of occupational psychology, this kind of fit discusses the individual's perception of the correspondence between the apparent skills, abilities, desires, and preferences of an employee with job requirements, typically indicated by work tasks [10, 43]. A fit between task demands and individual abilities demonstrates influence on the development of job-related attitudes and effects on work-related decisions [37], while decision-making itself is a knowledge-based process $[15,30]$ and an inherent element of high-level KW [2]. Thus, we question how abilities of PIIT, IT self-efficacy, and individual experiences with IT in everyday life complement demands-ability fit and enhance knowledge-based, human decision making in datafied knowledge work environments.

3.2.2 Decision support for datafied knowledge work from KMS and data-driven analytics. Humans traditionally interpret and synthesize information and data into knowledge [2], that serves as integral input for the process of decision-making in KW [15]. Knowledge as a strategic resource [17] is utilized through IT in KMS throughout the entire organization "to improve the creation, storage, sharing and use of knowledge to enhance some aspect of organizational performance and so extract business value" (32, p. 3). Research underlined incentives and an organizational, knowledge sharing culture as positive factors to achieve these goals of KMS 
$[2,22]$. Besides discussing the positive effect of individual IT abilities on datafication, the question arises how the future role of organizational KMS develops in datafied KW. We clarify in a first step, if datafication focusses on providing data for human decisions, or if datafication reaches farer and includes automated generating, delivering, and even machinery action and execution of algorithm-based decisions. This leads to the question how decisions are made, whereas degrees of automation play a crucial role to exemplify if datafication supports human decision leads to autonomous algorithmic decision-making. Decision support systems describe interactive computer-based systems that integrate "knowledge and theory from diverse areas such as database research, artificial intelligence, decision theory, economics, [...] and others" (25, p. 247), while the decision is still drawn by the knowledge worker in person. Research currently discusses the interplay of humans and algorithms in metahuman systems [28], another compelling socio-technical phenomenon that particularly addresses the consequences of how to balance human and machines in decision-making. In this regard allocation of decision rights, delegating, hierarchy, responsibility, and undesired outcomes of automated decisions are addressed. Whereas multiple dimensions of human data analytics competencies are proven to significantly enhance decision quality [15], automation by artificial intelligence is lastly supposed to rather minimize repetitive tasks of the remaining workers to increase their productivity efficiently, which is particularly outlined for high-level KW [20]. Consequently, for datafication of KW, we assume a supportive function of data analytics and AI, rather than a replacement of knowledge workers by full automation that is currently not to be foreseen. We therefore suppose a still existing but decreasing role of KMS, since humans will continue making decisions, but ever more supported by analytical tools that meet the specialized and individualized requirements for their datafied knowledge work tasks and (data-based) decisions than drawing on fairly generalized $K M S$.

\subsubsection{Autonomy effecting task definition and task} abilities in datafied knowledge work. An open question remains if the required digital competencies providing abilities to deal with algorithms, bots and data-models, in a creative way, alters the definition of the autonomy components in KW [14]. Digital abilities and ITcompetencies might increase in importance, while the need for constantly innovating, learning and teaching new practices, processes and approaches to tasks, in order to improve the outcomes, might decrease. In classic $\mathrm{KW}$ autonomy helped to define the task at hand, and to choose the abilities of how to solve the task - a social phenomenon. In datafied $\mathrm{KW}$ autonomy might only emerge in the technical component. As autonomy was seen as an important element to spark productivity and increase individual performance in classic knowledge work, an open question occurs of the importance of autonomy in datafied knowledge work.

3.2.4 Individual performance and productivity in datafied knowledge work. Demands-ability fit in general demonstrates coincidence with major attitudinal and behavioral conditions of work attitudes and behavior, such as job satisfaction, organizational commitment, or individual job performance [26, 37]. The area of best fit in figure 1, represents the area of maximum stimulation, challenge, and performance [7, 8]. As datafication is a technological-driven phenomenon enabled by developments in digital technologies, it remains an open question if the requirements of equal importance and balance between the social and technical to reach dual objectives of productivity and job-satisfaction are synchronously met [39] and as such leads to performance. Research shows that technological development outpaces the development of organizational structures and cultures to respond effectively and it raises concerns about the socio-technical fit. As our contingency framework covers individual, task-related, as well as organizational criteria that culminate in job performance $[7,8]$. We have put forward a path for investigating the importance of socio-technical fit for maximum performance. For future research into supplemented sociotechnical fit, we suggest exploring the outcome variable job-satisfaction alongside individual performance to assess if datafied knowledge work simultaneously produces well-being and job-satisfaction and hence lead to positive effects on job performance.

\section{Conclusion and future research}

The presented framework of datafied KW illustrates influential factors on job performance based on the contingency theory of action and job performance, thereby depicting attributes from three sub-dimensions of individual, job related, and organizational conditions. We enrich the traditional understanding of KW with a process model of non-standardized tasks and expand it through multi-level considerations from both the individual and the organizational level. Since competing in digital ecosystems represents an organization-spanning challenge, our assumptions around datafication of $\mathrm{KW}$ combine evolving determinants of the digitized organizational environment (DBS, data-based decision support, and traditional KMS) with changing job task definitions, individual abilities, and digital competences.

We propose the framework to be a guideline for both qualitative and quantitative future research through 
providing a structured perspective of current questions for exploring the socio-technical phenomenon of datafication of KW. The framework provides an elementary yet future model of determinants of productive datafied $\mathrm{KW}$. We explore this phenomenon from the overarching socio-technical perspective against the background of digital convergence, the increasing congruence of organizational structure with digital infrastructure. The subdivision of this phenomenon into the social artefact of KW and the technical artefact of algorithmic thinking allows us to develop a multilevel framework, that especially argues to understand the cross-sectional interweaving of data and IT with the organizational structure as the pivotal determinant of KW in times of datafication.

To further assess the conditions of contemporary decision making, we contribute with triggering the discussion around this integral part of $\mathrm{KW}$ in times of datafication. We pose future research directions to clarify how the increasing adoption of data-based decision support might influence conditions of human KW. While current research indicates that high-level $\mathrm{KW}$ will still be led by humans [20] rather than replaced by fully automated AI, it is of particular relevance to exemplify the growing interplay between "autonomous" algorithms and consequences for human autonomy in KW.

As contributions to theory, we extend the research on KW by transferring the contingency theory from the field of leadership to explore effects of datafication for advanced KW professionals. This theory allows us to structure datafied $\mathrm{KW}$ in a process-driven framework through discussing, integrating, and combining relevant operationalizations: We model $\mathrm{KW}$ as a process of job tasks, followed by abilities to fill the job demands, which results in individual performance. A combination of individual and organizational factors describes datafication, namely individual IT competencies (PIIT, IT self-efficacy, IT consumerization) as well as organizational determinants such as a DBS, KMS, and algorithmic, data-driven decision support (AI, data analytics).

For future research we particularly point out to investigate how requirements for individual job abilities (must) develop when data plays an increased magnifying role for knowledge workers' decision making. Through a focused discussion on IT-related competencies for productive $\mathrm{KW}$, we clearly delineate the field of datafication from $\mathrm{f}$ ully automated decision making by e.g. AI, while supposing that data analytics and machine learning will support the still human knowledge worker in drawing decisions from a data supply of extensive amount, rigor, and speed.

\section{References}

[1] Agarwal, R. and J. Prasad, "A Conceptual and Operational Definition of Personal Innovativeness in the Domain of Information Technology", Information Systems Research, 9(2), 1998, pp. 204-215.

[2] Alavi, M. and D.E. Leidner, "Review: Knowledge Management and Knowledge Management Systems: Conceptual Foundations and Research Issues", MIS Quarterly, 25(1), 2001, pp. 107-136.

[3] Alvesson, M. and J. Sandberg, "Generating research question through problematization", Academy of Management Review, 36(2), 2011, pp. 247-271.

[4] Bennis, W., "Leadership In A Digital World: Embracing Transparency And Adaptive Capacity", MIS Quarterly, 37(2), 2013, pp. 635-636.

[5] Bharadwaj, A.S., O.A. El Sawy, P.A. Pavlou, and N.V. Venkatraman, "Digital business strategy: toward a next generation of insights", MIS Quarterly, 37(2), 2013, pp. 471-482.

[6] Bonde Thylstrup, N., M. Flyverbom, and R. Helles, "Datafied knowledge production: Introduction to the special theme", Big Data \& Society, 6(2), 2019, 1-5.

[7] Boyatzis, R.E., The competent manager: A model for effective performance, John Wiley \& Sons, New York, USA, 1982.

[8] Boyatzis, R.E., "Managerial and Leadership Competencies: A Behavioral Approach to Emotional, Social and Cognitive Intelligence", Vision, 15(2), 2011, pp. 91-100.

[9] Brynjolfsson, E. and K. McElheran, "The Rapid Adoption of Data-Driven Decision-Making", American Economic Review, 106(5), 2016, pp. 133-139.

[10] Cable, D.M. and D.S. DeRue, "The Convergent and Discriminant Validity of Subjective Fit Perceptions", Journal of Applied Psychology, 87(5), 2002, pp. 875-884.

[11] Davenport, T.H., "Rethinking knowledge work: A strategic approach", McKinsey Quarterly, 1(11), 2011, pp. 88-99.

[12] Davenport, T.H. and J. Kirby, Only humans need apply: Winners and losers in the age of smart machines, Harper Business, New York, N.Y., 2016.

[13] Davenport, T.H. and L. Prusak, Working knowledge: How organizations manage what they know, Harvard Business Press, New York, N.Y., 1998.

[14] Drucker, P.F., "Knowledge-Worker Productivity", California Management Review, 41(2), 1999, pp. 79-94.

[15] Ghasemaghaei, M., S. Ebrahimi, and K. Hassanein, "Data analytics competency for improving firm decision making performance", The Journal of Strategic Information Systems, 27(1), 2018, pp. 101-113.

[16] Grant, A.M. and S.K. Parker, "Redesigning work design theories: the rise of relational and proactive perspectives", Academy of Management annals, 3(1), 2009, pp. 317-375.

[17] Grant, R.M., "Toward a knowledge-based theory of the firm", Strategic Management Journal, 17(S2), 1996, pp. 109122.

[18] Gregory, R.W., E. Kaganer, O. Henfridsson, and T.J. Ruch, "IT Consumerization and the Transformation of IT Governance", MIS Quarterly, 42(4), 2018, pp. 1225-1253.

[19] Hansen, M.T., N. Nohria, and T. Tierney, "What's your strategy for managing knowledge?", The knowledge management yearbook 2000-2001, 77(2), 1999, pp. 106-116. 
[20] Holford, W.D., "The future of human creative knowledge work within the digital economy", Futures, 105, 2019, pp. 143-154.

[21] Jacobides, M.G., C. Cennamo, and A. Gawer, "Towards a theory of ecosystems", Strategic Management Journal, 39(8), 2018, pp. 2255-2276.

[22] Kankanhalli, A., B.C.Y. Tan, and K.K. Wei, "Contributing Knowledge to Electronic Knowledge Repositories: An Empirical Investigation", MIS Quarterly, 29(1), 2005, pp. 113-143.

[23] Keen, P. and R. Williams, "Value Architectures For Digital Business: Beyond The Business Model", MIS Quarterly, 37(2), 2013, pp. 643-647.

[24] King, J.L., "CIO: Concept is over", Journal of Information Technology, 26(2), 2011, pp. 129-138.

[25] Kou, G., Y. Shi, and S. Wang, "Multiple criteria decision making and decision support systems - Guest editor's introduction", Decision Support Systems, 51(2), 2011, pp. 247249.

[26] Kristof-Brown, A.L., R.D. Zimmerman, and E.C. Johnson, "Consequences of individuals' fit at work: A meta-analysis of person-job, person-organization, person-group, and person-supervisor fit", Personnel Psychology, 58(2), 2005, pp. 281-342.

[27] Loebbecke, C. and A. Picot, "Reflections on societal and business model transformation arising from digitization and big data analytics: A research agenda", The Journal of Strategic Information Systems, 24(3), 2015, pp. 149-157.

[28] Lyytinen, K., J.V. Nickerson, and J.L. King, "Metahuman systems = humans + machines that learn", Journal of Information Technology, 2020.

[29] McAfee, A. and E. Brynjolfsson, "Big Data: The Management Revolution", Harvard Business Review, 90(10), 2012, pp. 60-68.

[30] Milkman, K.L., D. Chugh, and M.H. Bazerman, "How Can Decision Making Be Improved?", Perspectives on psychological science, 4(4), 2009, pp. 379-383.

[31] Monteiro, E., T. Østerlie, E. Parmiggiani, and M. Mikalsen, "Quantifying Quality: Towards a Post-humanist Perspective on Sensemaking", in Living with Monsters? Social Implications of Algorithmic Phenomena, Hybrid Agency, and the Performativity of Technology, U. Schultze, M. Aanestad, M. Mähring, C. Østerlund, and K. Riemer, Editors. 2018. Springer International Publishing: Cham.

[32] Newell, S., "Managing Knowledge and Managing Knowledge Work: What we know and what the Future holds", Journal of Information Technology, 30, 2015, pp. 1-17.

[33] Nonaka, I., "A Dynamic Theory of Organizational Knowledge Creation", Organization Science, 5(1), 1994, pp. 14-37.

[34] Pasmore, W., S. Winby, S.A. Mohrman, and R. Vanasse, "Reflections: Sociotechnical Systems Design and Organization Change", Journal of Change Management, 19(2), 2019, pp. 67-85.

[35] Petry, T., "Digital leadership", in Knowledge Management in Digital Change. 2018. Springer.

[36] Plesner, U. and E. Husted, Digital organizing: Revisiting themes in organization studies, Red Globe Press, 2020.
[37] Resick, C.J., B.B. Baltes, and C.W. Shantz, "Person-organization fit and work-related attitudes and decisions: examining interactive effects with job fit and conscientiousness", The Journal of applied psychology, 92(5), 2007, pp. 14461455 .

[38] Sanchez-Monedero, J. and L. Dencik, "The datafication of the workplace", White Paper?, 2019.

[39] Sarker, S., S. Chatterjee, X. Xiao, and A. Elbanna, "The Sociotechnical Axis of Cohesion for the IS Discipline: Its Historical Legacy and its Continued Relevance", MIS Quarterly, 43(3), 2019, pp. 695-719.

[40] Schultze, U., M. Aanestad, M. Mähring, C. Østerlund, and K. Riemer, eds., Living with Monsters? Social Implications of Algorithmic Phenomena, Hybrid Agency, and the Performativity of Technology, Springer International Publishing, Cham, 2018.

[41] Seran, S. and M. Izvercian, "Prosumer engagement in innovation strategies", Management Decision, 52(10), 2014, pp. 1968-1980.

[42] Snow, C.C., Ø.D. Fjeldstad, and A.M. Langer, "Designing the digital organization", Journal of Organization Design, 6(7), 2017.

[43] Sylva, H., S.T. Mol, D.N. Den Hartog, and L. Dorenbosch, "Person-job fit and proactive career behaviour: A dynamic approach", European Journal of Work and Organizational Psychology, 28(5), 2019, pp. 631-645.

[44] Tams, S., J.B. Thatcher, and K. Craig, "How and why trust matters in post-adoptive usage: The mediating roles of internal and external self-efficacy", The Journal of Strategic Information Systems, 27(2), 2018, pp. 170-190.

[45] Teece, D.J., "Business Models, Business Strategy and Innovation", Long Range Planning, 43(2-3), 2010, pp. 172-194. [46] Thatcher, J.B. and P.L. Perrewé, "An Empirical Examination of Individual Traits as Antecedents to Computer Anxiety and Computer Self-Efficacy", MIS Quarterly, 26(4), 2002, pp. 381-396.

[47] Tilson, D., K. Lyytinen, and C. Sørensen, "Research Commentary -Digital Infrastructures: The Missing IS Research Agenda", Information Systems Research, 21(4), 2010, pp. 748-759.

[48] Weinberger, D., "The problem with the data-informationknowledge-wisdom hierarchy", Harvard Business Review, 2, 2010.

[49] Wolf, M., R. Beck, and I. Pahlke, "Mindfully resisting the bandwagon: Reconceptualising IT innovation assimilation in highly turbulent environments", Journal of Information Technology, 27(3), 2012, pp. 213-235.

[50] Wunderlich, N. and R. Beck, "You'll Be Surprised - Digital Business Strategy as Driver of Organizational Innovativeness", Proceedings of the 51th Hawaii International Conference on System Sciences (HICSS 2018); Big Island, Hawaii, USA, 2018.

[51] Yoo, Y., R.J. Boland, K. Lyytinen, and A. Majchrzak, "Organizing for Innovation in the Digitized World", Organization Science, 23(5), 2012, pp. 1398-1408. 